\title{
A economia criativa sob a ótica das redes sociais dos produtores culturais de Brasília
}

\section{The creative economy under the optics of the social networks of cultural producers in Brasília}

\author{
Edgar Reyes Junior ${ }^{1}$ \\ Fagner Dias ${ }^{2}$ \\ Renata Gomes ${ }^{3}$
}

\begin{abstract}
Resumo
As relações profissionais podem gerar relações interpessoais, bem como o inverso também ocorre. O interesse pela economia criativa e pelo setor cultural tem crescido nos últimos anos, principalmente ao se considerar que o PIB criativo cresceu $69,8 \%$ de 2004 a 2013, e continua crescente, e o PIB nacional cresceu somente $36,4 \%$ no mesmo período. Por isso, este artigo objetiva realizar o mapeamento e a análise das relações e interações sociais na produção cultural de Brasília. O produtor cultural, na condição de quem produz eventos culturais, foi o objeto de análise. Este estudo é exploratório-descritivo, de cunho quali-quantitativo, no qual se utilizou o método bola de neve, por meio de entrevista aplicada a 40 produtores culturais de Brasília-DF. A partir dessa base e utilizando a análise de redes sociais (ARS), foi observada uma rede com 534 atores e ligações consistentes de uma rede sólida, permeada por outros profissionais atuantes na cadeia produtiva da cultura, com diferentes subgrupos. Obteve-se também o perfil sociodemográfico dos produtores, as características das empresas e a identificação das características dos atores centrais da rede.
\end{abstract}

Palavras-chave: Economia Criativa. Produtor cultural. Redes sociais. Relação interpessoal.

\begin{abstract}
Professional relationships can generate interpersonal relationships as well as in the opposite direction also occurs. Interest in the creative economy and in the cultural sector has grown in recent years, especially considering that the creative GDP grew $69.8 \%$ from 2004 to 2013 and national GDP only $36.4 \%$ in the same period, and continues to grow. Therefore, this article aims to map and analyze the relationships and social interactions in the cultural production of Brasilia. The cultural producer, on the condition of who produces cultural events, was the object of analysis. This is an exploratory-descriptive, qualitative-quantitative study, in which the snowball method was used, through an interview applied to 40 cultural producers in Brasilia-DF. From this base and using social network analysis (SNA), a network with 534 actors and consistent links of a solid network, permeated by other professionals working in the productive chain of culture, with different subgroups was observed. The sociodemographic profile of the producers, characteristics of the companies and the identification of the characteristics of the central actors of the network were also obtained.
\end{abstract}

Keywords: Creative economy. Cultural producer. Social networks. Interpersonal relationship.

Possui graduação em Administração de Empresas pela Universidade Salgado de Oliveira (2004), mestrado em Administração pela Universidade do Vale do Rio dos Sinos (2008) e doutorado em Administração pela Universidade do Vale do Rio dos Sinos (2012). Professor adjunto da Universidade de Brasília. Tem experiência em Administração, com ênfase em Estratégias de Relações Interorganizacionais, principalmente nos temas: confiança, redes, Relações Estado-Sociedade e área da Saúde. Afiliação: Programa de Pós Graduação em Administração da Universidade de Brasília - PPGA/UnB. Email: prof.edreyes@gmail.com

2 Possui graduação em Ciências Policiais pelo Instituto Superior de Ciências Policiais (2007) e Física pela Universidade de Brasília (2015), cursando mestrado em Administração pela Universidade de Brasília. Membro do Grupo de Pesquisa em Relações Interorganizacionais (GERIR/ IOR\&N) da UnB. Tem experiência em Administração, com ênfase em Estratégia nas Organizações, Marketing, Análise de Redes Sociais e Redes Interpessoais. Afiliação: Programa de Pós Graduação em Administração da Universidade de Brasília - PPGA/UnB. Email: fagner.pmdf@ gmail.com

Possui graduação em Administração de Empresas pela Universidade de Brasília (2015). Tem experiência na área de Administração, com ênfase em Redes Interpessoais, Análise de Redes Sociais, Economia Criativa, Produção Cultural e Gestão da Cultura. Áreas de interesse: Políticas Públicas para Cultura e negócios criativos. Afiliação: Programa de Pós Graduação em Administração da Universidade de Brasília PPGA/UnB. Email: rvg.renata@hotmail.com 


\section{Introdução}

Aumentar o PIB do Brasil é sinônimo de possibilidade de aumento de empregos e de crescimento do país (TEMER, 2018). Considerando essa importância e observando o mapeamento da indústria cultural do país de 2004 a 2013, o PIB criativo teve quase o dobro do aumento comparado ao PIB nacional, $69,8 \%$ e $36,4 \%$ respectivamente (FIRJAN, 2014). Assim, a produção cultural se mostra uma saída econômica aparentemente vantajosa para a economia nacional, enaltecendo a importância de analisar e descrever a sua estrutura.

A produção cultural exige, além de competências técnicas, articulação com diversos atores: fornecedores, governo, prestadores de serviços, patrocinadores, empresários e parceiros. Entretanto, essa articulação profissional pode se tornar uma relação interpessoal, assim como uma relação interpessoal pode proporcionar contatos profissionais. Focadas nos modelos de relacionamento entre atores sociais, as redes sociais vêm sendo exploradas pela ciência como opção à lógica do homem econômico, compreendido aqui pelo indivíduo desprovido de sensibilidade e direcionado apenas a ganhar dinheiro e satisfazer seus interesses. Estudos que se utilizam das redes para análise vêm crescendo nos EUA e na Europa e, desde então, também no Brasil (CLARE, 2012, CUCCIA\& RIZZO, 2015, KIM, 2015, LIMA, 2009, LIMA \& LOIOLA, 2013).

Para Marteleto (2001), as redes sociais são estabelecidas em um dado grupo por atores autônomos que se ligam por valores e interesses comuns, unindo ideias e recursos. Ao invés de valorizar as estruturas hierárquicas, as redes estimulam os elos informais e as relações interpessoais, por isso se observa as interações entre organizações e também entre os indivíduos que as compõe, com o intuito de apontar quais atores gozam de maior poder e influência no grupo. Além de método de pesquisa, a teoria de redes sociais busca conhecer os impactos que as relações sociais possuem em uma população.

De acordo com a UNCTAD (2012), o conceito de economia criativa é considerado em evolução, e tem como base os ativos criativos que, potencialmente, geram crescimento e desenvolvimento econômico. Sendo a produção cultural um dos eixos da indústria criativa, a qual se refere aos diversos setores econômicos do país que dependem da criatividade para se desenvolverem, e sua operação exige, por necessitar de diversos fornecedores e parceiros, uma boa capacidade relacional. Tal é a necessidade relacional e a falta de convergência sobre como e com que esforço cada ator social interage em rede, além da falta de uma determinação de fronteira dos envolvidos (PROCOPIUCK \& FREDER, 2014), que explorar tal rede torna-se de tamanha importância.

As sociedades artísticas não se consideravam como uma rede conectada, mas como interações específicas intracampos e pontuais. Os estudos científicos podem propor modelos para auxiliar questões clássicas das sociedades artísticas, como etapas de carreira, socialização, processos de criação e de execução, reconhecimento e mobilização de recursos (AZAM \& FEDERICO, 2014). Devido às características dos produtores culturais e à dificuldade em se definir e descrever tal população, em especial no DF, surge a seguinte questão de pesquisa: Como se comporta a rede de produtores culturais de diferentes linguagens no Distrito Federal?

O presente estudo tem como objetivo geral o mapeamento e análise das interações sociais na produção cultural do Distrito Federal, especificamente o mapeamento socioeconômico, e a analise da rede por meio dos indicadores de centralidade e poder.Tal estudo é de grande relevância, pois na atividade econômica criativa, a produção cultural apresenta-se como um dos subsetores mais importantes devido ao impacto no PIB de uma região, conforme demonstra o mapeamento criativo nacional (FIRJAN,2016). Inicialmente, a demonstração da simples existência desse setor já se torna relevante uma vez que é pouco analisado e teve considerável aumento de interesse nos estudos sobre redes de desenvolvimento econômico local e regional (HÁ, LEE \&FEIOCK, 2016). A indústria criativa tem sido vista como um importante tema no desenvolvimento urbano e de ações políticas relevantes para melhorar seu efeito positivo (LEE, 2015). Ainda é possível compreender melhor como cada um se comporta da rede. Afinal, em um ambiente de rede, compartilhar informação e conhecimento de forma eficiente entre os atores asseguram ganhos, valendo-se destas para reduzir incertezas e promover crescimento mútuo (TOMAEL \& MARTELETO, 2006). 
Para compreender os fluxos de informação em redes sociais é fundamental investigar as ligações e interações dos atores de uma rede social (SUGHARA, 2010).

\section{Referencial teórico}

\subsection{Economia Criativa}

Ao se falar em criatividade, Howkins (2010) defende que pode ser descrita, mas não definida, pois está sempre em uma situação condicional. A criatividade econômica é um processo de inovação nos negócios que almejam aumento da vantagem competitiva. Enquanto a criatividade cultural ou artística é a capacidade de desenvolver novas ideias em texto, imagem e som para compreender o mundo. E a criatividade científica é experimentação para a descoberta de novas soluções para problemas. Todas essas criatividades convergem na criatividade tecnológica, em maior ou menor intensidade, e se inter-relacionam entre si (UNCTAD, 2012).

Para Deheinzelin (2011), economia criativa é o conjunto de atividades valoradas pelos recursos intangíveis. A experiência, a diversidade cultural, o conhecimento e tudo aquilo que qualifica e diferencia pessoas, empreendimentos e comunidades é fonte de valoração. Temos economia criativa ao tratar de bens e serviços baseados na representatividade simbólica, referindo-se ao conjunto de atividades alicerçadas na criatividade, no talento ou na habilidade individual (MIGUEZ, 2007).

Historicamente, a Escola de Frankfurt ficou conhecida por sua análise da cultura de massa, mais especificamente pelo conceito de indústria cultural, que buscava integrar a teoria da cultura com a economia política e a psicologia social, em que adotavam a cultura como a totalidade dos recursos culturais servindo de mediadora entre a demanda comportamental da sociedade e a psique do indivíduo (MACHADO, 2009). Adorno e Horkheimer (1985) são frankfurtianos, e foram os primeiros a identificar e conceituar a indústria cultural como a produção massificada e uniforme de produtos culturais, ainda na década de 40 , voltadas para o controle social. Nessa abordagem, não há lugar para contemplar as disposições morais e os vínculos afetivos dos indivíduos sociais. Os frankfurtianos rejeitam a tradicionalidade, o afeto e a racionalidade de valor como significativas da ação, deixando-os essencialmente orientados pela racionalidade instrumental, obedecendo aos princípios da produção econômica geral e da lógica comercial do lucro, no qual tudo produzido pela indústria cultural seria considerado, integralmente, mercadoria (MACHADO, 2009).

A Federação das Indústrias do Rio de Janeiro [FIRJAN] (2014) usa a nomenclatura "indústria criativa" no sentido relacionado à "economia criativa", conforme os conceitos supracitados de Adorno e Horkheimer (1985), podendo também ser chamado de "setor criativo". Este trabalho, entretanto, restringe-se a pesquisar o setor cultural, que está contido no setor criativo. O setor cultural abrange, conforme o MinC (2012), os segmentos ligados à produção artístico-cultural, compreendidos por música, dança, teatro, ópera, circo, pintura, fotografia e cinema, excluindo demais atividades e expressões ligadas à indústria de conteúdo, ao design, à arquitetura, às novas mídias, entre outros.

A definição da expressão "produtos culturais" pode ser utilizada quando é possível aceitar, no contexto, o entendimento de cultura tanto em seu sentido psicológico quanto em seu sentido funcional. São atributos do produto cultural, consoante a UNCTAD (2012): 1) Uso da criatividade humana no processo de produção; 2) Além de utilitários, são responsáveis pela transmissão de uma mensagem simbólica e; 3) Presença de propriedade intelectual do produtor responsável.

Entre os sete países pertencentes ao Mercosul, o Brasil é o único que possui saldo positivo no comércio de produtos culturais. A UNCTAD (2012) afirma que existem mais de 400 membros pertencentes à rede Mercosul Cultural, que trabalham visando o fortalecimento de informações culturais entre Argentina, Brasil, Chile, Colômbia, Peru, Uruguai e Venezuela. Uma vez compreendidos os fundamentos da economia criativa, faz-se necessário a compreensão do setor criativo no Brasil.

O campo da cultura no território nacional é complexo e composto por subcampos específicos, sendo cada um uma linguagem cultural distinta, e por agentes diversos que disputam entre si a favor de interesses próprios, como o Estado, o artista, o mercado, os coletivos culturais, entre outros (SANTOS, BISPO, \& DOURADO, 2013). Ainda em 2004, o MinC identificou mais de 320.000 negócios culturais no país, sendo responsáveis por 1,6 milhões de empregos (UNCTAD, 2012). Dados como estes são importantes para o 
reconhecimento do setor não só como uma vertente importante dentro do contexto de desenvolvimento econômico e social do Brasil, mas como atividade produtiva que gera contratações, renda e receitas de exportações (UNCTAD, 2012).

O mapeamento do setor criativo mostrou que, em 2013, havia 251 mil empresas criativas formalizadas no Brasil, $69,1 \%$ a mais do que em 2004, e que essas foram responsáveis por 2,6\% do PIB nacional em 2013, o equivalente a R\$ 126 bilhões. Isoladamente, o PIB da indústria criativa aumentou 69,8\% de 2004 a 2013, enquanto o PIB total do país cresceu 36,4\% no mesmo período (FIRJAN, 2014).

Em uma análise mais atual da FIRJAN (2016), do biênio 2013-2015, a participação do PIB criativo estimado no PIB brasileiro cresceu de 2,56\% para 2,64\%, passando de 126 para 155,6 bilhões do PIB nacional. Dentre outros dados, observa-se que a classe criativa tem salário médio de $R \$ 6.270$, mais de duas vezes e meia a remuneração média dos empregados formais brasileiros, $R \$$ 2.451.Em Brasília (DF), a participação do PIB criativo no PIB do DF subiu de 2,9\% em 2013 para 3,1\% em 2015 (FIRJAN, 2016).

O MinC (2012) fez o acompanhamento do crescimento do PIB cultural de 2005 a 2010, e verificou aumento de $6,13 \%$ ao ano, também superior a média anual do PIB total do Brasil, que foi de $4,3 \%$, ratificando os dados anteriormente apresentados. A análise econômica do setor criativo verificou uma tendência de aumento na robustez econômica nos empreendimentos que possuem a criatividade como principal atividade do processo produtivo, ganhando ainda maior representatividade no PIB nos próximos anos (MINC, 2012).

A maioria desses profissionais criativos atua em indústrias clássicas e, por isso, são denominados "clássico-criativos" (FIRJAN, 2014), comprovando a relevância da diferenciação criativa na geração de valor de produtos ou serviços. Entretanto, é sabido que o PIB mensura apenas as atividades formais de ocupação.

Conforme a FIRJAN (2016), o setor criativo empregava 851,2 mil profissionais no Brasil em 2015, mas apenas $23,4 \%$ desse total trabalham em empresas puramente criativas, como escritórios de design, produtoras audiovisuais ou agências de publicidade.

Silva (2012) afirma a complexidade de se mensurar o mercado de trabalho cultural justamente pela própria dificuldade de se definir quais profissões podem ser incluídas, se apenas atividades estritamente culturais ou se todo o setor cultural, que abrange o grupo de atividades que o assiste. Agora, incluindo as ocupações informais da economia, obtém-se dados que mostram a real relevância do setor criativo para a economia e o desenvolvimento do país. Silva (2012) mostra que, em 2008, havia mais de dois milhões de profissionais criativos no Brasil e que o setor cresceu, de 2002 a 2008, 27\%, considerando o mercado criativo formal e informal.

\subsection{O Produtor Cultural}

O produtor cultural é o agente social provido de capitais próprios, entendidos aqui por recursos financeiros, materiais, culturais e simbólicos, que atua no setor cultural com um posicionamento determinado (SANTOS, BISPO, \& DOURADO, 2013). A produção de um evento cultural é mais do que planejar, programar, executar e monitorar uma série de atividades realizadas em um local devido e para um público delimitado. O produtor deve pensar no evento como uma atividade econômica, além de social, responsável por criar benfeitorias para a cidade onde é produzido, para o comércio local, como restaurantes, hotéis e demais empreendedores, e para a comunidade (BRITTO \& FONTES, 2002).

Cada um desses microuniversos da produção cultural (artistas, público, poder público, espaços culturais, empresas patrocinadoras e mídia) possui linguagem e método próprios, tornando a comunicação entre o mundo criativo e o executivo nada fácil (AVELAR, 2010). Olivieri e Natale (2013) afirmam que o produtor cultural é a ponte entre esses mundos e que deve ter visão integral de todo o processo e autonomia para intervir quando necessário. Em outras palavras, ele desempenha um papel de interface nesta conexão.

Santos, Bispo e Dourado (2013) ratificam a força da ligação entre o produtor e o poder público, pois este é o grande financiador do setor. Esse perfil foi fortificado e estruturado a partir de 2003, com Gilberto Gil no cargo de ministro da Cultura, sucedido por Juca Ferreira, principalmente para o segmento da cultura popular. Entretanto, ressaltam que o poder do Estado e das empresas financiadoras acaba se sobressaindo, 
exercendo o papel de produtores e fazendo com que o profissional autônomo tenha de disputar e demarcar seu espaço dentro da cadeia produtiva.

Na pesquisa realizada no setor cultural em Pernambuco, verificou-se que o governo ou produz ele mesmo seus eventos, ou contrata empresas específicas sem a realização de licitação aberta, dificultando o desenvolvimento e a profissionalização das empresas de produção e dos produtores independentes, de acordo com produtores locais (Santos, Bispo \& Dourado, 2013). Para esses produtores, tal atitude faz com que os interesses dos agentes financiadores sejam priorizados nos eventos, ao invés da concepção artística e cultural, corroborando com a teoria supracitada de Adorno e Horkheimer (1985).

Mesmo assim, ainda há instituições que preferem desconsiderar o papel de mediação do produtor cultural, por acreditarem que a negociação com esse profissional será mais onerosa para a empresa, porque ele tentará conseguir mais benefícios para si, para os artistas e para os técnicos. Optam por produzir os próprios eventos e acordar diretamente com os artistas, que muitas vezes não têm aptidão para negócios. Estes, por sua vez, também invalidam a função do produtor cultural, buscando capacitação na área e se autoproduzindo. $\mathrm{O}$ artista acredita que o produtor cultural desvirtua e não respeita seu trabalho, tanto o processo de criação quanto o produto final, tratando-o como mero comércio (Santos, Bispo \& Dourado, 2013).

O cenário de desvalorização do produtor cultural favorece a informalidade da profissão, legitimando os dados sobre ocupação informal no setor apresentados anteriormente. Justifica-se assim a análise exploratória das redes sociais formadas por esses produtores, uma vez que a informalidade acaba por tornar a população dos produtores culturais, em uma população de difícil observação.

\section{Redes sociais}

As redes sociais são fruto das relações interpessoais que ocorrem dentro dos círculos sociais. Elas se iniciam do contato entre duas pessoas que, mesmo que tenha ocorrido por intermédio de um terceiro agente, torna-se uma ligação independente de sua origem, podendo se desfazer após um período, ou se intensificar e tornar-se íntima (GROSSETTI, 2014). A formação das redes pode se dar por meio de contatos, gerando ligações entre os atores (REYES JR. et al., 2012). Esses contatos possuem características diversas, as quais possibilitam diferentes formas de ligação, construídas e reconstruídas constantemente, impulsionadas por relacionamentos tais como: amizade, compartilhamento de informações e relações de trabalho (KADUSHIN, 2012).

A busca por socialização, aceitação, status e poder não pode ser desmembrada das ações econômicas dentro da economia social moderna, pois tais ações acontecem intrarrede. Dessa forma, a imersão social (social embeddedness) e a construção social das instituições econômicas são definidas como conceitoschave para as novas analogias (LIMA, 2009).

Wasserman e Faust (1994) definem que as redes sociais são formadas por dois elementos: atores e suas conexões. O primeiro elemento trata dos grupos, pessoas ou instituições pertencentes às redes; já o segundo, das ligações formadas entre eles devido a suas interações. Lazzarini (2008) usa a nomenclatura de nós e laços para representar, respectivamente, os mesmos elementos.

A análise das redes sociais (ARS) permite investigar as estruturas macro e micro dentro das relações sociais, pois utiliza os conhecimentos da Psicologia Social, que avalia as características dessas estruturas. As Ciências Sociais, de uma forma geral, possuem abordagem mais tradicional, analisando a estrutura macro e micro das relações de maneira isolada e dicotômica, assim como indivíduo versus sociedade e ator versus estrutura. Usam modelos explicativos que foram construídos a partir de modelos causais, que não são capazes de explicar acontecimentos complexos e multidimensionais como as relações sociais (MARTELETO, 2001; REYES JR. et al., 2012).

Neste estudo, a análise é de uma rede egocêntrica de relações diáticas. A rede egocêntrica é o nível mais simples de rede, onde o ator central (ego) possui relação direta com outros atores (alter). A díade, ou relação diática, implica em uma análise de dois atores e os possíveis lações desenvolvidos entre eles. Para analisar a rede, é necessário utilizar as informações sobre cada díade e a fim de explicar as relações estruturais de toda a rede (WASSERMAN \& FAUST, 1994; KADUSHIN, 2012). 
As relações em redes de relacionamento são baseadas na confiança, e tal confiança pode ser representada por meio do compartilhamento de valores e normas coletivas, fazendo o papel da coordenação da cooperação e colaboração em ambientes onde existe incerteza (REED, 2001). A confiança tem um efeito no campo do comportamento organizacional que excede $60 \%$, em magnitude, outros efeitos na área (DE JONG, DIRKS, \& GILLESPIE, 2016), sendo consenso sobre os inúmeros benefícios que a confiança pode proporcionar às relações entre os atores sociais. A presença de confiança influencia positivamente processos cognitivos, atitudinais e resultados coletivos no ambiente organizacional (NASKRENT \& SIEbelt, 2011).

As posições dentro da rede podem definir atores com maior poder e influência sobre os outros (KADUSHIN, 2012). Para Mascovici (1985), essa situação é evidenciada sobre objetos sociais, pois são desprovidos de parâmetros claros para a formação de um conceito sobre eles, e a cultura é um exemplo de objeto social. Sendo assim, os indivíduos que não possuem um posicionamento claro a respeito de algum desses objetos acabam se valendo dos pontos de vista de um ator da rede, ou de um grupo. Para verificar tais posições de destaque na rede social, alguns dos métodos propostos são as análises das centralidades dos atores. Centralidade refere-se à posição do ator na rede com relação aos demais (FREEMAN, 1979) e pode ser determinada por atributos como grau, intermediação (FREEMAN, 1979) e poder (WASSERMAN \& FAUST, 1994; BONACICH, 1987).

A difusão de inovações na sociedade acontece por meio das redes interpessoais, pois, à medida que vão tendo acesso a inovações, os atores as propagam aos demais conhecidos. Assim sendo, não só inovações, mas também ideias e informações serão multiplicadas de forma mais rápida (VALENTE, 1996). Borgatti (2013) chama os atores líderes de opinião de "atores chaves"(sic) e entende o poder de difusão que possuem, tanto para conectar quanto para fragmentar a rede. Para isso, usa medidas que vão além da centralidade, como as medidas de alcance, para conectar, e as medidas de fragmentação e distância, para fragmentar a rede.

Poucos estudos empregaram a análise de redes sociais para compreender, avaliar e mensurar campos pertencentes à cultura. As principais pesquisas são na indústria cinematográfica. Apenas duas são brasileiras e nenhuma das pesquisas relaciona as características sociodemográficas e o desempenho dos atores com a análise da rede, que é o que este estudo se dispõe a executar.

\section{Procedimentos metodológicos}

A pesquisa empírica foi realizada por meio de uma amostra de 40 produtores culturais do DF, que foi selecionada através do método de amostragem em bola de neve (snowball sampling). Esse método é utilizado para populações pouco visíveis (GOODMAN, 1961), seja por motivos sociais, sejam legais, como a falta de formalização da atividade, chamadas de populações escondidas.

O método só é aplicável em populações em que seus membros sejam capazes de identificarem uns aos outros, pois são os próprios membros da amostra que indicam outros membros para integrarem o plano amostral (GOODMAN, 1961). Fernandes e Carvalho (2000) citam a criação de mundos próprios pelos membros de uma população escondida. A existência desse mundo social próprio dos produtores culturais é o que justifica a escolha da bola de neve como método de amostragem.

Para iniciar a construção da amostra, foi preciso identificar alguns atores pertencentes à população de produtores culturais em Brasília, chamados sementes, que indicaram outros atores que faziam parte do público-alvo da pesquisa e que eles conheciam, formando a primeira onda (GOODMAN, 1961), e assim sucessivamente, até que se obtivesse o número de respondentes necessário para a pesquisa. A rede gerada pelos 40 respondentes, iniciada com 6 produtores sementes, é formada por 534 atores, obtidos após a citação de familiares, amigos e conhecidos próximos aos entrevistados e que são pertencentes à cadeia produtiva da cultura. Esses profissionais são financiadores, gestores, músicos, artistas cênicos, djs, fornecedores, cantores, assessores de imprensa, fotógrafos, dançarinos, artistas plásticos, incentivadores e parceiros, permitindo-se assim uma representação bastante significativa da economia cultural do DF.

$O$ instrumento de coleta de dados utilizado foi o formulário de entrevista estruturada, composto por 43 questões, 24 fechadas e 19 abertas, todas baseadas na escala de relacionamento de colaboração no 
terceiro setor (REYES JR, 2012) e que, conforme o autor, pode ser usado para outros relacionamento de cunho econômico. As questões fechadas usaram uma escala Likert, com valoração de um a cinco pontos para cada pergunta, em que um é o menor grau e cinco o maior grau, em perguntas como dificuldade de realização do evento, vantagens da localização, proximidade com o público, fomento, entre outros tratados nos resultados.

O DF foi divido em zona central e satélites no questionário, e foram consideradas como zona central todas as regiões administrativas com renda per capta média acima de $R \$ 3.500,00$. Conforme CODEPLAN (2014), são elas: Brasília, Lago Sul, Lago Norte, Sudoeste/ Octogonal e Park Way. As demais regiões administrativas compuseram o grupo de satélites. Tal divisão fez-se viável para este estudo, pois o objetivo que se teve ao perguntar onde as pessoas moravam e faziam seu trabalho foi saber justamente qual o padrão de vida desses profissionais e qual classe de público visam atingir.

A centralidade de cada agente na rede é medida com o objetivo de se identificar a relevância que cada ator possui dentro da rede. Quanto maior a relevância, maior a centralidade. Há tipos de centralidade que podem ser calculados, e cada uma se refere a um tipo de comportamento do agente dentro da rede (ROSSONI \& GUARIDO FILHO, 2007). Para a obtenção dos índices de centralidade, foram usados os softwares UCINET 6.340 / NETDRAW 3.28.Os tipos de centralidade que foram discutidos e analisados neste trabalho são: centralidade de grau, centralidade de intermediação, centralidade geodésica e poder de Bonacich.

\section{Resultados}

\subsection{Características das Organizações}

Dentre as organizações analisadas, em maior quantidade estão as microempresas, com 33,3\%. Em segundo lugar, as ONGs e OSCIPs, com 23,1\%. Em terceiro lugar estão os microempreendedores individuais, com $20,5 \%$, e os potenciais empresários em seguida, com $15,4 \%$. Pequeno e médio porte somaram $7,7 \%$, e não foi encontrada nenhuma empresa de grande porte do setor no DF. Ressalta-se ainda que $90 \%$ delas foram abertas com capital próprio do empreendedor.

Sobre a quantidade de colaboradores fixos que cada uma dessas organizações agrega, é importante frisar que o termo colaborador é usado justamente por considerar também, além de funcionários clássicos, grupos independentes de trabalho focados em parceria e sem relação de contratação, mas com assiduidade. Das empresas, $28,2 \%$ delas não possui nenhum colaborador fixo além do próprio empresário-fundador, e $43,6 \%$ possui de um a cinco colaboradores. Empatadas com 12,8\% estão os negócios que possuem na faixa de seis a dez funcionários e de 11 a 50 . Empresas com mais de 50 colaboradores fixos compõem 2,6\% da amostra. Infere-se, portanto, que as empresas do setor possuem um pequeno quadro de colaboradores e que, quando precisam de mais mão-de-obra, fazem contratações temporárias, por projeto.

Considerando o tempo de existência no mercado do DF, as empresas do setor são relativamente novas. As com menos de dois anos de existência representam $13 \%$ das organizações. As empresas que possuem entre dois e cinco anos são maioria no estudo, alcançando $35 \%$ da amostra, bem próximo da porcentagem que figura as empresas de seis a dez anos, $33 \%$. Os negócios com mais de dez anos de existência no mercado correspondem a $20 \%$ do total, e a mais antiga delas tem 37 anos.

Ao contrapor a faixa etária dos produtores e o tempo de existência das organizações em que trabalham, observa-se que a taxa de produtores de 25 a 35 anos é apenas $0,5 \%$ maior do que a taxa de empresas abertas entre dois e dez anos, sendo elas praticamente iguais. E 85\% dessas mesmas empresas estão nas categorias de potencial empresário, MEI ou microempresa, corroborando com a afirmação de que o setor tem elevado nível de empreendedorismo e que o perfil empreendedor é de negócios pequenos, recentes, mas já estabelecidos e fundados por jovens adultos.

As três maiores dificuldades entre os produtores entrevistados são questões comerciais, indispensáveis para a viabilização financeira das produções. Dos entrevistados, 11 mencionaram a burocracia como fator de grande desafio para a execução do trabalho, principalmente os atores que obtém recursos por meio de 
editais públicos, os que prestam serviço para o governo e os que precisam de alvará para a realização de seus projetos.

Também foram citados como dificuldades: a mensuração de custo e de valor do produto cultural; a inexistência de piso salarial estabelecido; a falta de políticas públicas continuadas que visem à sustentabilidade econômica e à retroalimentação do setor; a escassez de advogados especializados no ramo de direito autoral; a pouca disponibilidade de espaços culturais e a existência de "panelinhas" que restringem as participações profissionais e sociais a pequenos grupos e impedem que haja uma sinergia maior do setor.

Constata-se que os produtores culturais da amostra possuem grau elevado de dificuldade para a realização de seus projetos, pois $80 \%$ dos entrevistados apresentaram dificuldade média individual entre três e quatro, e $17,5 \%$ dos respondentes têm uma dificuldade média individual de dois.

A respeito da vantagem de localização, observa-se que o maior benefício existente é a proximidade com o público-alvo, atingindo a média de 3,9. O segundo colocado, com distância considerável do primeiro, é a existência de fomento e de parceiros comerciais, com média de 2,9. Disponibilidade de serviços técnicos especializados está em terceiro lugar, com 2,7 de média, seguido pela proximidade com patrocinadores e apoiadores. Empatados com 2,5 está a qualidade de mão-de-obra de produção e de serviços commodities, compreendidos pelos serviços básicos e sem qualificação, como limpeza, transporte, etc.

A proximidade com centros de formação, como universidades, centros de pesquisa e unidades de informação, está em sexto lugar na classificação de vantagens, com 2,4 de média geral, igual a infraestrutura existente na cidade. $\mathrm{O}$ baixo custo dos profissionais de produção e o baixo custo de serviços técnicos especializados não são considerados favoráveis no DF, com média geral de 2,0. Pior ainda está o baixo custo dos serviços commodities, aparece com a pior média de vantagem, de 1,9.

O custo de todos os serviços citados está entre as menores vantagens locais, sendo possível inferir que o preço de tais serviços é mais caro do que a média, perdendo apenas para as grandes metrópoles, conforme frase de A14 "os custos aqui são caros, exceto se compararmos ao Rio de Janeiro ou a São Paulo". Um dos motivos identificados para esse alto custo é o oligopólio do mercado, confirmado no discurso de A12 e A15: "para cada tipo de serviço há um ou dois fornecedores bons, a gente fica na mão deles" e "o serviço é caro e eles não fazem direito, atrasam e ainda precisamos ficar fiscalizando se está sendo feito corretamente", respectivamente.

A maior vantagem de se produzir eventos culturais no DF é a presença do público-alvo, principalmente porque parte dos produtores entrevistados planejam e adequam seus projetos visando justamente a melhor forma de atingir o público desejado, comprovado pelo depoimento de A9: "nós desenvolvemos nossos projetos pensando na dinâmica da cidade e das pessoas daqui, na carência que havia de eventos diurnos em que se pudessem ouvir boas músicas e que os artistas independentes da cidade pudessem expor e vender seus trabalhos".

Em relação aos quesitos qualidade, preço e confiança, foram geradas duas análises. A primeira avalia todos os quesitos para cada perfil de serviço contratado e a segunda, a relevância de cada quesito.

As notas mais altas de importância foram dadas à contratação de serviços de produção, obtendo média de 4,41. Imediatamente após está a contratação de serviços técnicos especializados, com média 4,38 de importância. A contratação de serviços commodities está depois e empata com a importância dada à realização de parcerias com outras empresas e/ou produtores, com média de 4,26 cada.

Na segunda análise, foi possível observar que a confiança é a variável mais relevante para as contratações de forma geral no setor de produção cultural, com média de 4,65, na escala de um a cinco. Em segundo lugar, está a qualidade, com 4,47 de média. $O$ preço e a relação custo-benefício entre parceiros apresentam-se em último lugar, com 3,87.

Dessa forma, é possível afirmar que há maior exigência na contratação do prestador de serviço de produção do que dos demais profissionais e nas formações de parcerias. E o quesito mais importante para a escolha de quaisquer profissionais ou de empresas parceiras é a confiança. Além disso, o preço ou o custo-benefício é o menos considerado no momento das decisões de contratação. 


\subsection{Características da rede}

Quanto à rede como um todo, observa-se que é composta por 40 respondentes e 494 atores extrarrede indicados pelos entrevistados.

Dada a elevada centralidade de atores extrarrede nesse conjunto de interações, infere-se que outros perfis pertencentes à cadeia produtiva da cultura acabam assumindo grande importância, como músicos, artistas cênicos, djs, fornecedores, cantores, assessores de imprensa, fotógrafos, dançarinos, artistas plásticos, financiadores, gestores, incentivadores e parceiros. Observando somente a rede dos respondentes, dividiu-a em três facções, baseando-se nas forças das conexões relacionais, conforme figura 1.

O conjunto em preto, composto por 21 respondentes, é o subgrupo com mais conexões da rede. Nele estão os agentes realizadores de produções viabilizadas pelo FAC ou demais recursos públicos, por isso executam ações de contrapartida social e possuem orçamento elevado. Os produtores mais velhos da rede estão nesse grupo e o produtor mais novo tem 28 anos, gerando uma média etária de 36,6 anos. A maioria deles já ultrapassou a faixa de idade majoritária da amostra, que vai até os 35 anos.

O grupo vermelho evidencia os atores cujas produções são privadas, de alto custo e com faturamento elevado, composto pela minoria da amostra, seis atores. Todos são formalizados e a maioria está nas categorias de micro e pequenas empresas, que permitem faturamentos mais altos, tanto que todos os seis residem na zona central do DF. A linguagem de trabalho predominante no grupo é a de shows e festas, e esses produtores foram alguns dos que afirmaram que nunca pagam para entrar em produções de conhecidos, ou que pagam raramente.

Já o grupo azul, formado pelos 13 entrevistados restantes, representa os produtores independentes, com eventos sem custo muito alto, de acesso gratuito ou com preços acessíveis. Logo, não há faturamento volumoso, mas é lucrativo. São produções com propostas de ocupação e de mudança do comportamento social. A grande maioria dos agentes do grupo possui outra atividade remunerada além da função de produtor cultural, o que faz com a maioria exerça a atividade de produção informalmente, caracterizando-se como potenciais empresários. Mas também há, no grupo, microempreendedores individuais e microempresas.

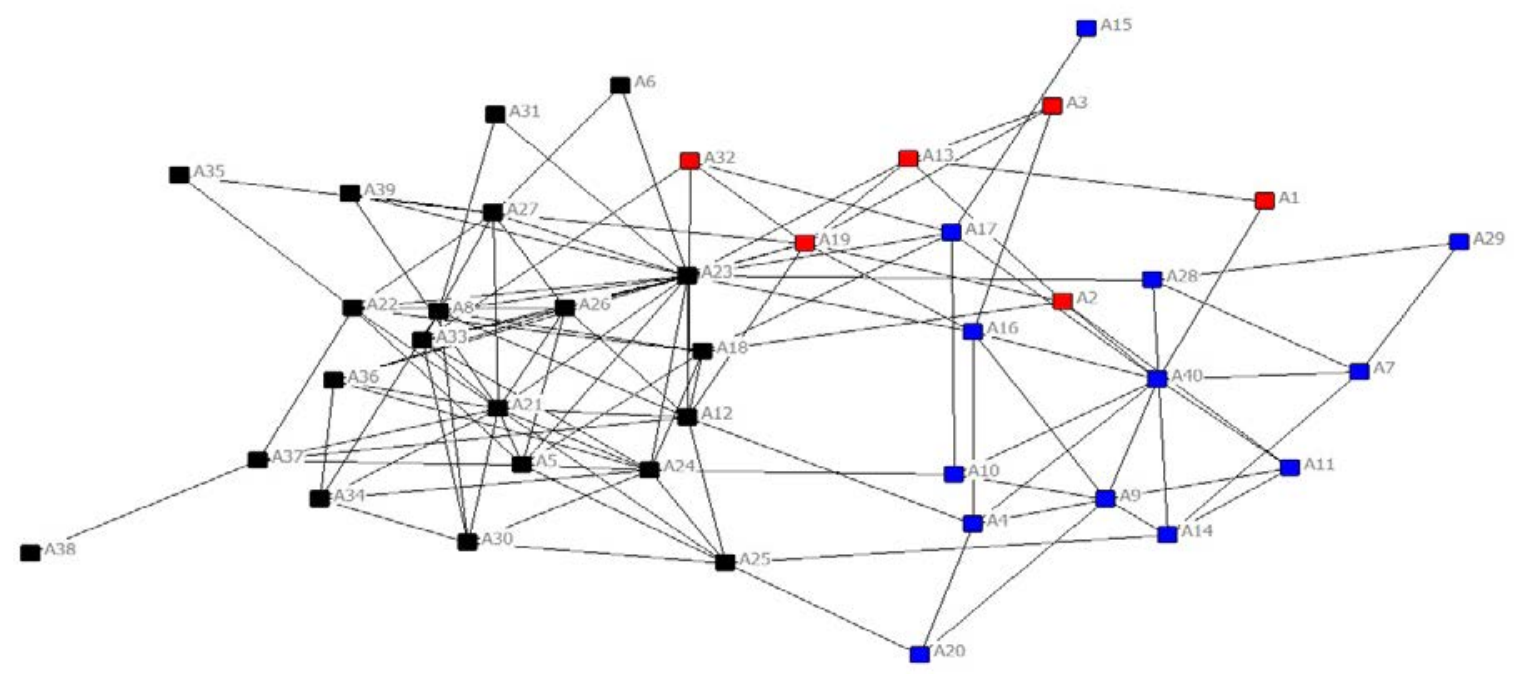

Figura 1: Rede dos respondentes em três facções

Fonte: Elaborado pelos autores.

São notados alguns atores de cada grupo que se relacionam com atores de todos os grupos,formando pontes preciosas de comunicação da rede pelo fato de conseguirem integrar grupos que não pertencem ao mesmo nicho e não são tão próximos. São eles: A2, A12, A13, A16, A17, A19, A23 e A32. Apenas dois membros da rede estão conectados a ela por apenas uma ligação, A15 e A38. Todo o restante da amostra conhece ou é conhecida por, pelo menos, dois outros agentes.

Realizou-se também a análise expandida da rede, incluindo todos os atores citados com índice de centralidade maior que 0,5 . Composta por 76 atores, a rede foi dividida em quatro facções, considerando 
as forças das ligações entre os agentes. Na figura 2, notam-se as quatro facções representadas em cinza, preto, vermelho e azul.

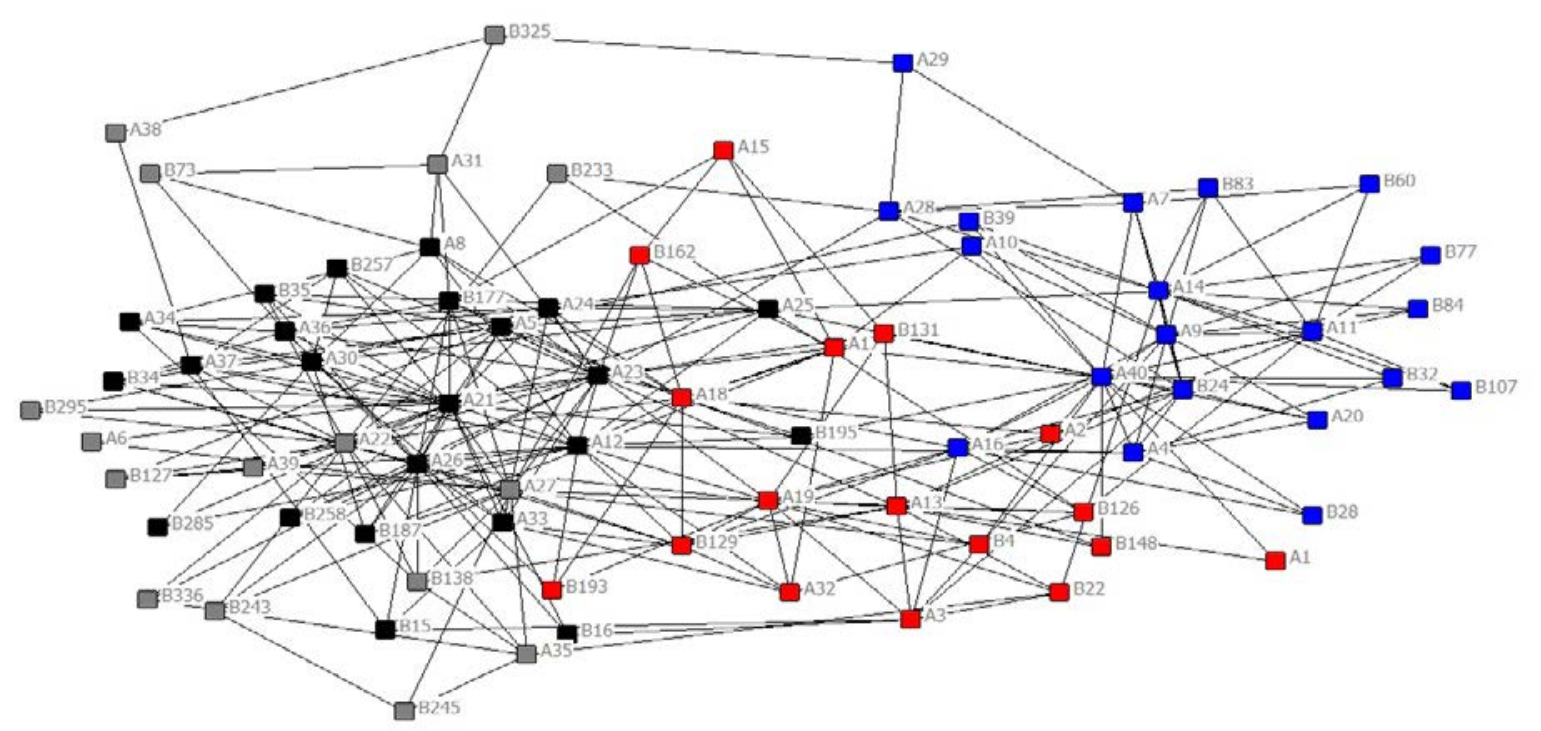

Figura 2: Rede com principais agentes extrarrede em quatro facções

Fonte: Elaborado pelos autores.

No conjunto cinza, com 16 atores, a maioria são mulheres e as linguagens artísticas dos agentes estão divididas entre shows e teatro de grande porte. É interessante observar que esse grupo está bem entremeado com os agentes em preto por apresentar singularidades, como a de gênero, há uma proximidade maior.

Já o conjunto preto é o composto por 24 produtores de shows de grande porte e seus fornecedores: assessores de imprensa, cantores, técnicos de som e de estrutura. A média de idade desse grupo é a mais elevada da rede. A maior parte dos atores, tanto em cinza quanto em preto, são de faixa etária maior que a média, estão a mais tempo no setor e utilizam mais recursos públicos.

O grupamento em vermelho representa os produtores de festas noturnas grandes e os djs de maior apelo no mercado atual. Esses 17 atores também possuem uma boa interação com os grupos preto e cinza pelo fato das linguagens se relacionarem. Há produções feitas em parcerias e alguns djs tocam nos intervalos ou em pistas alternativas do show. Entre eles, percebe-se que as distâncias das ligações são maiores.

Os 20 atores em azul são os pequenos produtores independentes e seus parceiros e fornecedores que, majoritariamente, também são amigos, como djs que também são produtores e participam de coletivos, tocando em eventos de outros produtores ou em seus próprios eventos. Esses dois grupos também possuem relações mais próximas entre si, mas não tão densas quanto às interações entre os pretos e os cinzas.

\subsubsection{Centralidade de grau}

O ator A40, que utiliza a linguagem de festas, é o que detém o maior índice de centralidade de grau, com índice de 8,63, seguido de A21, que produz shows, com 7,88 e de A9, com 6,38, que trabalha com festas. Empatados no ranking de centralidade estão A22 e A23, com índice 10.442. Eles são ambos do ramo de música. A14 tem índice 6,0; A13, 5,63, e A12, 5,44. O único ator com linguagem diferente de festas, shows e música é o A13, que é multilinguagens. Apenas A14 é homem.

$\mathrm{O}$ ator A9 e A14 promovem eventos frequentes com formatos e estruturas pensados não só no mercado local aberto a novos negócios e com boa aceitação a inovações, mas também na necessidade de movimentar a cidade, gerando uma mudança no comportamento cultural do público, conforme as seguintes falas de A9 e A14, respectivamente: "nós desenvolvemos nossos projetos pensando na dinâmica da cidade e das pessoas daqui, na carência que havia de eventos diurnos em que se pudesse ouvir boas músicas e que os artistas independentes da cidade pudessem expor e vender seus trabalhos" e "as festas são para 
o público universitário, temos muitos jovens na cidade". Assim, pode-se afirmar serem esses os atores, conforme Wasserman e Faust (1994), são aqueles com maior potencial de articulação.

\subsubsection{Centralidade de intermediação}

Entre os dez atores com maior centralidade de intermediação estão, em ordem decrescente, A23, A21, A40, A25, A12, A37, A28, A31. Seus índices de intermediação são de 20,45; 13,23; 12,73; 10,52; 9,16; 8,$82 ; 8,66$ e 8,24 .

A maioria dos atores com maior centralidade de grau também possuem altos índices de centralidade de intermediação. Os três primeiros colocados são mulheres, junto com A12. Os únicos atores que não apareceram no topo anteriormente foram: A25, A37, A28 e A31. Por outro lado, a linguagem ficou ainda mais homogênea, perdendo os agentes multilinguagens, aumentando os de shows e música, e ganhando um agente do teatro, $\mathrm{A} 31$, um produtor sábio e respeitado pela cadeia produtiva.

A12 é produtora cultural e dá mérito às amizades por ter iniciado no ramo. Conforme sua fala: "Eu conheço todo mundo, consigo produzir um evento para 2 mil pessoas com 5 telefonemas", pois obtendo contato com agentes de linguagens distintas, de fornecedores e de gente de diferentes localidades, como sendo ponte entre produtores da zona central e produtores das cidades satélites. Justificando, assim, sua capacidade de atuar como ponte entre demais elementos da rede descrita por Wasserman e Faust (1994).

\subsubsection{Centralidade geodésica}

O agente cultural com maior centralidade a partir da centralidade dos demais agentes da rede é A21, com 49,17. Em seguida, tem-se A23 e A26, respectivamente com 43,44 e 37,43. O quarto e quinto lugares são ocupados por A22, com 32,53, e A12, com 31,36. Seguidos por A27, com 28,60; A5, com 25,76 e, por fim, A24, com 24,67. Entre esses 8 atores, todos são mulheres.

A21 e A23 apenas trocaram de posição em relação ao ranking de centralidade de intermediação, e A21 possui a segunda maior centralidade de grau, reforçando seu lugar de destaque e prestígio dentro da rede. Nota-se que surge um novo agente dentro do ranking, o A5. Apesar de A5 não estar entre os mais centrais da rede nem presente nos caminhos mais curtos para alcançar demais atores, seus contatos são pessoas de influência, dando-lhe prestígio na rede.

\subsubsection{Poder de Bonacich}

Considerando o exposto por Pinto e Junqueira (2009), foi calculado o poder normal de Bonacich dos atores e A40 teve o índice mensurado em 171,41, com diferença do segundo maior, A21, que obteve 134,15. A14 atingiu 115,52, empatado com A9. A13 e A22 tiveram, ambos, 108,06 e, por ultimo, A30 e A34, ambos com 100,61.

Faz-se importante destacar que A40 e A13 possuem mais relações com contatos em nível de "conhecidos próximos" com os demais atores da rede. Não produzem com frequência, mas convivem frequentemente com os agentes do setor.

Na presente pesquisa, o poder de Bonacich ratifica o poder dos atores A40, A21, A9, A22, A14 e A13, observado anteriormente na centralidade de grau de Wasserman e Faust (1994). Dessa forma, concluise que esses são, de fato, os atores mais influentes da rede obtida pela amostra utilizada de produtores culturais. Dos seis, apenas um é homem. Entre as mulheres, metade trabalha mais com verba pública e a outra metade centra-se em verba privada. A maioria está na faixa etária média da amostra e mora na zona central. 
Tabela 1:

Ordem decrescente das centralidades da rede de produtores culturais

\begin{tabular}{cccccccc}
\hline \multicolumn{2}{c}{ GRAU } & \multicolumn{2}{c}{ INTERMEDIAÇÃO } & \multicolumn{2}{c}{ GEODÉSICA } & \multicolumn{2}{c}{ PODER DE BONACICH } \\
\hline Ator & Índice & Ator & Índice & Ator & Índice & Ator & Índice \\
\hline A40 & 8,63 & A23 & 20,45 & A21 & 49,17 & A40 & 171,41 \\
A21 & 7,88 & A21 & 13,23 & A23 & 43,44 & A21 & 134,15 \\
A9 & 6,38 & A40 & 12,73 & A26 & 37,43 & A14 & 115,52 \\
A22 & 6,44 & A25 & 10,52 & A22 & 32,53 & A9 & 115,52 \\
A23 & 6,44 & A12 & 9,16 & A12 & 31,36 & A13 & 108,06 \\
A14 & 6,00 & A37 & 8,82 & A27 & 28,60 & A22 & 108,06 \\
A13 & 5,63 & A28 & 8,66 & A5 & 25,76 & A30 & 100,61 \\
A12 & 5,44 & A31 & 8,24 & A24 & 24,67 & A34 & 100,61 \\
\hline
\end{tabular}

Fonte: Elaborado pelos autores.

\section{Discussão}

$\mathrm{Na}$ análise descritiva, identificou-se que os produtores são, em sua maioria, jovens adultos, com alto nível de escolaridade, do sexo masculino, residentes nas zonas nobres do DF, com carreira já estabelecida e que não possuem familiares atuando no setor. Há predomínio de microempresas jovens, porém estabelecidas no mercado, com poucos funcionários, que atuam na zona central do DF, possuem dificuldades em suas operações comerciais e consideram elevados os custos com prestadores de serviços na cidade. Mas são beneficiados pela proximidade com o público-alvo, com mecanismos de fomento e pela a existência de bons técnicos na cidade.

A importância da confiança nos trabalhos em grupo, afirmada por De Jong, Dirks, \& Gillespie (2016) e sua influência nos processos cognitivos, atitudinais e resultados coletivos no ambiente da organização (NaskreNT \& SIEBELT, 2011), afloram nos discursos dos atores da rede dos produtores culturais ao afirmarem que valorizam mais a confiança que possuem por um profissional do que preço ou qualidade na contratação de um serviço.

O presente estudo corrobora com o que foi encontrado por Cuccia e Rizzo (2015), que a competição pelos fundos públicos e privados era a via preferida a do autofinanciamento em produtores culturais da Sicília na Itália, ao observar que a presente rede de produtores culturais brasileiros respondentes teve pouco mais da metade de suas produções financiadas pelo governo, e as restantes com maioria de financiamento do setor privado, restando poucos produtores que se autofinanciam.

Os produtores culturais do DF são beneficiados pela proximidade com o público-alvo, com mecanismos de fomento e pela a existência de bons técnicos na cidade. A concentração da produção cultural na Zona Central, então, pode estar relacionada à vasta concentração de pessoas, recursos e infra-estrutura enraizadas em uma localidade territorial, igualmente verificado por Clare (2013), quando observada a busca por aglomeração e meio social de produtores culturais, funcionários de mídia e publicidade.

A rede é intensamente permeada de ligações entre os atores e há forte presença de outros profissionais, mas relacionados com o setor produtivo. Os produtores de música, shows e festas prevalecem sobre os demais. Apesar das barreiras que dificultam mulheres a atingir posições mais altas na hierarquia organizacional (HENDERSON, FERREIRA \& DUTRA, 2016), observou-se a supremacia das mulheres em posições estratégicas na rede de produtores culturais. Logo, acredita-se que a ausência de uma estrutura organizacional explícita pode ter facilitado o rompimento das dificuldades, dando espaço para as características não sexuais. 


\section{Conclusão}

Ao analisar a rede social de produtores culturais, os atores mais poderosos na rede produzem festas, shows e músicas, sendo esses setores os que têm maior fluxo de caixa e patrocínio. São, em sua maioria, mulheres com bons relacionamentos e patrocínio, rompendo a estrutura tradicional com a prevalência de homens nas principais posições (HENDERSON, FERREIRA \& DUTRA, 2016).

Este trabalho pode contribuir para o produtor saber quais relações estabelecer para melhor se relacionar com a rede e atingir seus objetivos profissionais e pessoais, assim como para que se perceba o administrador como profissional competente para atuar enquanto produtor e gestor cultural com mais conhecimento técnico.

O poder público, enquanto financiador da cultura, é favorecido pelo estudo, pois Ihe permite identificar os subgrupos e analisar a rede enquanto facções, para constatar uma nova forma de financiamento focada nos grupos com menos recursos e, simultaneamente, em um mesmo segmento. Enquanto propositor de estratégias para o incentivo e fomento à cultura, pode ser percebida a movimentação da rede, os segmentos com mais dificuldades de desempenho e, com a identificação a ajuda dos atores da rede com mais influência, executar mudanças efetivas de forma mais natural. Ademais, consolida os estudos do DF enquanto polo criativo e cultural, com um aglomerado produtivo consolidado, bem relacionado. Além disso, traz a análise de rede social e das relações interpessoais para o setor da economia criativa.

A pesquisa aproxima a economia criativa e a produção cultural da Administração, propondo que se entenda que essa é uma área de atuação profissional do administrador, contribuindo para que a academia perceba o desenvolvimento crescente e o poder econômico da economia criativa, focando o ensino e pesquisas nessa área, com disciplinas, seminários e estágios; assim como para que o setor privado reconheça na cultura uma forma de investimento viável.

\section{Referências}

ADORNO, T. W.; HORKHEIMER, M. Dialética do Esclarecimento: fragmentos filosóficos. $1^{\text {a }}$ ed. Rio de Janeiro: Zahar, 1985.

AVELAR, R. O avesso da cena: notas sobre produção e gestão cultural. Belo Horizonte, MG: Duo Editorial, 2010.

AZAM, M.; FEDERICO, A. Sociologíadel arte y análisis de redes sociales. REDES -Revista Hispana para el Análisis de Redes Sociales, Barcelona, v. 25, n. 2, p.1-22, Jul.-Dic. 2014.

BONACICH, P. Power and centrality: a family of measures. The American Journal of

Sociology, Chicago, v.92, n.1,p.1170-1182., Mar. 1987

BORGATTI, S. P. El problema delactor clave. REDES -Revista Hispana para el Análisis de Redes Sociales, Barcelona,v.24, n.2, p.1-20, Dic. 2013.

BRITTO, J.; FONTES, N. Estratégias para eventos: uma ótica do marketing e do turismo. São Paulo, SP: Aleph, 2002.

CLARE, K. The essential role of place within the creative industries: Boundaries, networks and play. J. Cities, [S.I], v.34, p. 52-57, Oct. 2013.

COMPANHIA DE PLANEJAMENTO DO DISTRITO FEDERAL (CODEPLAN). Anuário estatístico 2014. Disponível em : < http://www.codeplan.df.gov.br/areas-tematicas/informacoes-estatisticas.html>. Acesso em 16 de jun. 2015.

COSTA, A. D.; SANTOS, E. R. S. Economia criativa: novas oportunidades baseadas no capital intelectual. Economia \& Tecnologia, Curitiba, v.25, n.7, p.179-186. abr./jun. 2011.

CUCCIA, T., RIZZO, I. Less might be better: sustainable funding strategies for cultural producers, City, Culture and Society, [S.I], v. 7, n.2, p.109-116, Jun. 2016,. 
DE JONG, B. A.; DIRKS, K. T.; GILLESPIE, N. Trust and team performance: A meta-analysis of main effects, moderators, and covariates. Journal of Applied Psychology, [S.I], v.101, n.8, p.1134-1150. Aug. 2016.

DEHEINZELIN, L. Economia criativa e métodos para dar uma mão ao futuro. Redige, [S.I], v.2, n.2, p. 343-360, Ago. 2011.

FERNANDES, L.; CARVALHO, M. C. Por onde anda o que se oculta: o acesso a mundos sociais de consumidores problemáticos de drogas através do método do snowball. Revista Toxicodependências, Lisboa, v.6, n. 3, p.17-28. 2000.

FEDERAÇÃO DAS INDÚSTRIAS DO RIO DE JANEIRO (FIRJAN). Mapeamento da indústria criativa no Brasil. Federação das indústrias do Estado do Rio de Janeiro: Sistema Firjan, Dezembro, 2014.

FEDERAÇÃO DAS INDÚSTRIAS DO RIO DE JANEIRO (FIRJAN). Mapeamento da indústria criativa no Brasil. Federação das indústrias do Estado do Rio de Janeiro: Sistema Firjan, Dezembro., 2016.

FREEMAN, L. C. Centrality in social networks: conceptual clarification. Social Networks, [S.I], v.1, p. 215-239.1978/1979.

GOODMAN, L. A. Snowball sampling. The Annals of Mathematical Statistics, [S.I], v.32, n.1, p. 148170, 1961.

GROSSETTI, M. ¿De dónde vienen las relaciones sociales? Un estudio de las redes personales en el área de Toulouse (Francia). REDES -Revista Hispana para el Análisis de Redes Sociales, Barcelona, v.25, n. 1, Jun. 2014.

HA, H.; LEE, I. W.; FEIOCK, R. C. Organizational Network Activities for Local Economic Development. Economic Development Quarterly, [S.I], v.30, n. 1, p.15-31. 2016.

HENDERSON, P.A.; FERREIRA, M.A.A.; DUTRA, J.S. As barreiras para a ascensão da mulher a posições hierárquicas: um estudo sob a ótica da gestão da diversidade no Brasil. Revista de Administração da UFSM. Santa Maria, v.9, n.3, p.89-505, Jul. - Set. 2016.

HOWKINS, J..Creative Ecologies: where thinking is a proper job. New York: Transaction Publications, 2010. 167p.

KADUSHIN, C. Understanding social networks: theories, concepts, and findings. New York, NY: Oxford University Press. 2012. 264p.

LAZZARINI, S. G. Empresas em rede. São Paulo: Cengage Learning, 2008.

LEE, M. Fostering connectivity: a social network analysisofentrepreneurs in creative industries. International Journal of Cultural Policy. [S.I], v.21, n.2, p.139-152. 2015.

LIMA, C. L. C. Redes sociais e aglomerações produtivas culturais: proposição de método de pesquisa e aplicação ao caso da produção de filmes em Salvador. 2009. 345f. Tese (Doutorado em em Cultura e Sociedade) - Universidade Federal da Bahia, Salvador, 2009. Disponível em: <https:// repositorio.ufba.br/ri/handle/ri/8692>. Acesso em: 07 maio 2018.

LIMA, C. L.C.; LOIOLA, E. Análise de redes sociais para o segmento cultural. Revista Pensamento \& Realidade, São Paulo, Ano XVI, v.28, n.4, p.37-47. 2013

MACHADO, R. M. Da indústria cultural à economia criativa. ALCEU, Rio de Janeiro, v.9, n.18, p.83-95, jan./jun. 2009.

MARTELETO, R. M. Análise de redes sociais: aplicação nos estudos de transferência de informação.

Ciência da Informação, Brasília, v. 30, n. 1, p. 71-81, jan./abr,. 2001.

MIGUEZ, P. Economia criativa: uma discussão preliminar. In: NUSSBAUMER, G. M. (Org.).Teorias e políticas da cultura: visões multidisciplinares. Salvador: EDUFBA. 2007. p. 95-114. (Coleção CULT). 
MINISTÉRIO DA CULTURA (MinC). Plano da Secretaria da Economia Criativa (SEC):políticas, diretrizes e ações 2011 a 2014. 2a ed. Brasília: Ministério da Cultura, 2012.

NASKRENT, J.; SIEBELT, P. The Influence of Commitment, Trust, Satisfaction, and Involvement on Donor Retention. Voluntas: International Journal of Voluntary and Nonprofit Organizations, [S.I], v.22, n.4, p.757-778. Dec.2011.

PINTO, A. M. G.; JUNQUEIRA, L. A. P. Relações de poder em uma rede do terceiro setor: um estudo de caso. Revista de Administração Pública - RAP, Rio de Janeiro, v.43, n.5, p.1091-1116, Set./Out.2009.

PROCOPIUCK, M.; FREDER, S.M. (2014) Economia criativa: modelo federal brasileiro e a importância das discussões frente a referenciais internacionais. Cadernos do CEOM, Chapecó-SC, n.27, v.40, Histórias Locais e Imaginário Social, p. 227-251, 2014.

REED, M. I. Organization, trust and control: a realist analysis. Organization Studies, [S.I], v.22, n.2, p.201-228. Mar. 2001.

REYES JR, E. As relações interpessoais em redes de apoio ao terceiro setor. 2012. 191f. Tese (Doutorado em Administração) - Universidade do Vale do Rio dos Sinos - UNISINOS, São Leopoldo-RS, 2012. Disponível: < http://www.repositorio.jesuita.org.br/bitstream/handle/UNISINOS/3377/Edgar\%20 Reyes\%20Junior.pdf?sequence=1\&isAllowed=y>. Acesso: 5 maio 2018.

REYES JR, E.;GONÇALO, C. R. ;BRANDÃO, C. N. Mapeando as relações sociais em aglomerados de empresas. REDES - Revista Hispana para el Análisis de Redes Sociales, v.23, n.6, p.178-201, Dec. 2012.

ROSSONI, L.; GUARIDO FILHO, E. R. Cooperação interinstitucional no campo da pesquisa em estratégia. Revista de Administração de Empresas - RAE, São Paulo, SP, v.47, n.4, p.74-88, Out./Dez. 2007.

SANTOS, E. C.; BISPO, D. A.; DOURADO, D. C. P. A posição do agente produtor cultural no campo da cultura pernambucano. Revista Pensamento \& Realidade, São Paulo, ano XVI, v.28, n.4, p.55-69, 2013.

SILVA, F. A. B.. Desenvolvimento e cultura: linhas gerais para um mapeamento conceitual e empírico. Latitude, Maceió- AL, v.6, n.2, p.6-21, 2012

SUGAHARA, R.S.; VERGUEIRO, W. Aspectos conceituais e metodológicos de redes sociais e sua influência no estudo de fluxos de informação. Revista Digital de Biblioteconomia e Ciência da Informação, Campinas, v.7, n. 2, p. 102-117, jan./jun. 2010

TEMER, M. Ordem é progresso. Folha de São Paulo, São Paulo, 18 abr. 2018. Disponível em: <http:// www2.planalto.gov.br/acompanhe-planalto/noticias/2018/03/presidente-destaca-fim-da-recessao-eafirma-que-objetivo-do-governo-e-desenvolver-o-brasil>. Acesso em: 5 maio 2018.

TOMAÉL, M. I.; MARTELETO, R.M. Redes sociais: posições dos atores no fluxo da informação. Enc. Bibli: R. Eletr. Bibliotecon. Ci. Inf., Florianopolis, n. esp., p.75-91.1º sem, 2006.

UNITED NATIONS CONFERENCE ON TRADE AND DEVELOPMENT (UNCTAD). Relatório de economia criativa 2010: economia criativa, uma opção de desenvolvimento. Brasília: Secretaria da Economia Criativa/Minc; São Paulo: Itaú Cultural. 2012.

VALENTE, T. W. Social network thresholds in the diffusion of innovations. Social Networks, [S.I], v. 18, n.1, p.60-89, Jan. 1996.

WASSERMAN, S. ;FAUST, K. Social Network Analysis: methods and applications. Cambridge: Cambrigde University Press. 1994. 